\title{
Subjective cognitive decline as a predictor of future cognitive decline A systematic review
}

\author{
Vladimir Anatolevich Parfenov ${ }^{1}{ }^{10}$, Vladimir Vladimirovich Zakharov ${ }^{10}$, \\ Anastasia Romanovna Kabaeva1 ${ }^{10}$, Natalya Vasilyevna Vakhnina1 ${ }^{10}$
}

\begin{abstract}
Over 44 million people suffer from dementia around the world. Researchers estimated that there will be 48.1 million people with dementia by 2020 and 90.3 million by 2040. In addition to dementia, mild cognitive impairment (MCI) and subjective cognitive decline $(\mathrm{SCD})$ relate to cognitive impairment. It has been established that $\mathrm{MCl}$ precedes dementia, however the significance of SCD is still unclear. Recent studies suggest that SCD could be a risk factor for objective cognitive impairment. SCD is defined as a self-estimated decline in cognitive capacity in comparison to an individual's previous level of functioning, which cannot be determined by neuropsychological tests. Objectives: To perform a systematic review of prospective longitudinal cohort studies that assessed the risk of $\mathrm{MCl}$ and dementia among people with SCD. Methods: A search was carried out for all available peer-reviewed articles in English related to SCD in PubMed and PsychINF0 databases from database initiation through January 2020. The keywords used for the search were 'subjective cognitive (or memory) impairment (or decline or complaints)'. Three authors separately determined the inclusion or exclusion of all articles retrieved for full-text evaluation. Results: The chance of progression to dementia in the SCD group was 2.17 (95\% confidence interval [95\% Cl] 1.53-3.07; $\mathrm{p}<0.05$ ) compared to normal aging. Furthermore, the SCD group was 2.15 times more likely to progress to $\mathrm{MCl}$ than the group without SCD (95\% $\mathrm{Cl} 1.39-3.30 ; \mathrm{p}=0.005)$. Conclusions: SCD might precede cognitive impairment, however, more detailed longitudinal studies should be conducted.
\end{abstract}

Keywords: cognition, dementia, cognitive dysfunction, aging, Alzheimer disease.

\section{DECLÍNIO COGNITIVO SUBJETIVO COMO PREDITOR DE FUTURO DECLíNIO COGNITIVO: UMA REVISÃO SISTEMÁTICA}

RESUMO. Mais de 44 milhões de pessoas sofrem de demência em todo 0 mundo. Pesquisadores estimam que haverá 48,1 milhões de pessoas com demência até 2020 e 90,3 milhões até 2040. Além da demência, 0 comprometimento cognitivo leve (CCL) e o declínio cognitivo subjetivo (DCS) estão relacionados ao comprometimento cognitivo. Foi estabelecido que 0 CCL precede a demência, porém a significância do DCS ainda não é clara. Estudos recentes sugerem que o DCS pode ser um fator de risco para comprometimento cognitivo objetivo. DCS é definido como um declínio auto-estimado da capacidade cognitiva em comparação com o nível anterior de funcionamento do indivíduo, que não pode ser determinado por testes neuropsicológicos. Objetivos: Realizar uma revisão sistemática de estudos prospectivos de coorte longitudinal que avaliaram o risco de CCL e demência entre pessoas com DCS. Métodos: Foram pesquisados todos os artigos revisados por pares disponíveis em inglês relacionados com DCS nos bancos de dados PubMed e PsychINF0 desde 0 início do banco de dados até janeiro de 2020. As palavras-chave utilizadas para a pesquisa foram "declínio cognitivo (ou de memória) subjetivo (ou comprometimento ou queixas)". Três autores determinaram separadamente a inclusão ou exclusão de todos os artigos que foram recuperados para avaliação em texto completo. Resultados: A chance de progressão para demência no grupo com DCS foi de 2,17 (intervalo de confiança de 95\% [IC95\%] 1,53-3,07; $p<0,05$ ) em comparação ao envelhecimento normal. Além disso, o grupo com DCS teve 2,15 vezes mais chances de progredir para CCL do que o grupo sem DCS (IC95\% $1,39-3,30 ; p=0,005)$. Conclusões: 0 DCS pode preceder o comprometimento cognitivo, no entanto, estudos longitudinais mais detalhados devem ser realizados.

Palavras-chave: cognição, demência, comprometimento cognitivo leve, envelhecimento, doença de Alzheimer

\footnotetext{
This study was conducted at the Sechenov First Moscow State Medical University.

'Sechenov First Moscow State Medical University - Moscow, Moskva, Russian Federation.
}

Anastasia Romanovna Kabaeva. Rossolimost St., 11-1 - 119021 Moscow - Russia. E-mail: kabaeva.anastasia@gmail.com

Disclosure: The authors report no conflict of interests.

Funding: none.

Received on April 4, 2020. Accepted in its final form on May 18, 2020. 


\section{INTRODUCTION}

$\mathrm{O}$ ver 44 million people worldwide have dementia. ${ }^{1}$ Researchers estimated that there will be 48.1 million people with dementia by 2020 and 90.3 million by $2040 .{ }^{1}$ Cognitive impairment is a very common cause of disability in the elderly.

It is well known that in the most common dementing disorders, e.g. in Alzheimer disease, clinical symptoms develop only after a long period of silent progressive brain damage. It has been established that mild cognitive impairment (MCI) precedes dementia; however, the significance of subjective cognitive decline (SCD) is still unclear.

Recent studies suggest that SCD could be the earliest symptom of the dementing disorder..$^{2-5}$ Reisberg et al., in 1982 and 1986, assumed that subjective complaints constitute the second stage of dementia according to the Global Deterioration Scale and precede objective cognitive decline. ${ }^{6,7}$

Considering SCD as a preclinical stage of a dementing disorder, a working group of SCD researchers published key definitions and a conceptual framework for research on SCD. ${ }^{8}$ SCD was defined as a self-estimated decline in cognitive capacity compared to and individual's previous level of functioning, which cannot be determined by neuropsychological tests. This condition was thought to occur when mild neuronal damage can be compensated functionally.

Several studies have shown that the prevalence of SCD is relatively high in a common elderly population. ${ }^{9-11}$ SCD could precede cognitive impairments of different etiologies (Alzheimer disease, vascular dementia, Lewy body dementia). However, SCD is an unspecific symptom and can be a result of the normal aging process or can be caused by conditions other than cognitive impairment, such as psychiatric disorders (depression, anxiety, and neuroticism), sleep problems, medication, or substance abuse..$^{8,11-13}$

The main goal of this study was to establish relations between SCD and objective cognitive impairment and examin the ability of SCD to predict MCI or dementia.

\section{METHODS}

We performed a detailed review of all available peer-reviewed articles available in English that referred to SCD in PubMed and PsychINFO databases from the beginning of the database through January 2020. The keywords used for the search were 'subjective cognitive (or memory) impairment (or decline or complaints)'. After acquiring the initial search results, the titles and abstracts of the articles were evaluated for suitability against the selection criteria. Full-text articles were then retrieved and assessed for inclusion. Three authors separately determined the inclusion or exclusion of all articles retrieved for full-text evaluation.

The quality of the studies was assessed by 2 reviewer authors using the Newcastle-Ottawa Scale (NOS), as recommended by the Cochrane Non-Randomized Studies Methods Working Group. Inclusion criteria were:

- Prospective longitudinal cohort studies published from January 2006 to January 2020;

- Follow-up period of 12 months and longer;

- Presence of a control group.

Studies where participants had baseline objective cognitive decline were excluded, as well as studies that included participants with SCD and other coexisting diseases, which could be a cause of memory complaints.

Data extraction was performed using a designed form by two authors. The information was collected about study details (year of the study, follow-up period, settings, method of SCD assessment, method of cognitive function assessment, MCI and dementia criteria), and demographic features (number of participants in SCD and control groups, mean age, percentage of females, mean Mini-Mental State Examination [MMSE] score in the SCD group). Results of the study (number of cases from both groups that converted to MCI and dementia) were accurately extracted. The reviewers encountered disagreement such as differences in selection of time points, control groups, scales, and whether to include a study in the review. Disagreements about data extraction were solved by consensus or by the decision of a third reviewer. In case of possible duplications, only one main study was included.

SCD was defined by the criteria used in each study. $\mathrm{MCI}$ was defined using Petersen criteria. ${ }^{14}$ The amount of dementia conversion cases was determined by the criteria used in each study.

Three main types of calculations were performed. First, cumulative conversion rates of SCD to dementia or to $\mathrm{MCI}$ were calculated. This parameter shows how many participants with SCD develop objective cognitive impairment during follow-up. Secondly, cumulative conversion rates of control for dementia or $\mathrm{MCI}$ were calculated. Finally, the relative risks of dementia or $\mathrm{MCI}$ were calculated. This statistical parameter indicates whether participants in the SCD group are more likely to develop dementia or MCI than participants without SCD.

Besides cumulative conversion rates, annual conversion rates were calculated for all kinds of outcomes. The annual conversion rate was calculated by dividing the number of subjects who progressed by the follow-up period of each subject. 
A weighted proportion analysis (DerSimonian-Laird model) was used in this study. The data set's heterogeneity was measured using the $\mathrm{I}^{2}$ parameter. Publication bias was assessed via Egger's and Egger-Harbord's tests and funnel plot inspection.

Due to the possible heterogeneity of the results, the relative risk was calculated for each dementia criteria that were used in the studies. The Knapp and Hartung adjustment was also used to account for uncertainty in the assessment of residual heterogeneity.

The statistical software StatsDirect was used to create the figures.

\section{RESULTS}

A total of 106 potentially eligible articles from keyword search were identified, which referred to the association between SCD and objective cognitive decline. Twenty-five articles were not available in the full version. Eighty-one full-text articles were retrieved. Seventy-one studies were excluded for not meeting the study selection criteria. In the excluded articles, 33 reports were not observational cohort studies; 8 studies were held before 2006; 20 studies had no control group; 4 studies were not prospective; 4 studies had unclear results; 1 study duplicated results of the included study; 1 study had follow-up time less than 12 months. As a result, 10 articles were included in our systematic review. ${ }^{15-24}$ Of these 10 articles, 4 studies considered SCD progression to dementia, 3 studies evaluated the conversion of SCD to MCI or dementia, and 2 studies analyzed the association between SCD and MCI. The stages of study selection are presented in Figure 1.

A total of 8,128 people participated in the included studies. SCD groups included 4,331 individuals and control groups included 3,797 ones. The mean age of participants with SCD was $73.68 \pm 6.26$ years, and the mean percentage of females in the studies was $58.51 \%$. The mean age of the control group subjects was $72.92 \pm 6.07$ years. The mean baseline MMSE of individuals with and without SCD was $28.5 \pm 1.8$ and $28.7 \pm 1.4$, respectively. The mean education level of SCD participants from 5 studies was $13.78 \pm 3.02$ years. Participants from the studies were recruited mostly from the community, but there were also participants from general practice, memory clinics. Healthy controls were recruited mostly from the community, general practice. The mean follow-up time in dementia studies was 5.27 years, and in MCI studies, 4.91 years. Of the different criteria commonly used for dementia diagnosis, the authors of the included studies used the Diagnostic and Statistical Manual of Mental Disorders $4^{\text {th }}$ Edition (DSM-IV), the International Classification of Diseases, $10^{\text {th }}$ Edition (ICD-10), the Clinical Dementia Rating (CDR), the Mini-Mental State Examination (MMSE), Neurological and Communicative Disorders and Stroke and The Alzheimer's Disease and Related Disorders Association Criteria (NINCDS-ADRDA), Brief Cognitive Rating Scale (BCRS). For MCI diagnosis, the authors applied Petersen, CDR, and NIA-AA criteria developed by the working group in $\mathrm{MCI}$ of the European Alzheimer's Disease Consortium. More detailed characteristics of the included studies are presented in Table 1.

\section{Analysis of subjective cognitive decline progression to dementia}

The following results were obtained from the analysis of 8 studies.

Pooled cumulative conversion rate of SCD for dementia was 7.23\% (95\%CI 3.64-12.04) (Figure 2). Heterogeneity was high $\left(\mathrm{I}^{2}=93.30 \%\right.$; $95 \% \mathrm{CI}$ 89.70-95.20) and there was some evidence of bias (Harbord-Egger bias=3.89; $\mathrm{p}=0.16$ ). Annual conversion rate for dementia among SCD participants was $1.12 \%$ (95\%CI 0.81-1.49). Heterogeneity was not high $\left(\mathrm{I}^{2}=0.00 \%\right.$; 95\%CI 0.00-56.30).

Cumulative conversion rate for dementia in the control group was $2.02 \%$ (95\%CI 0.44-4.73). Heterogeneity was

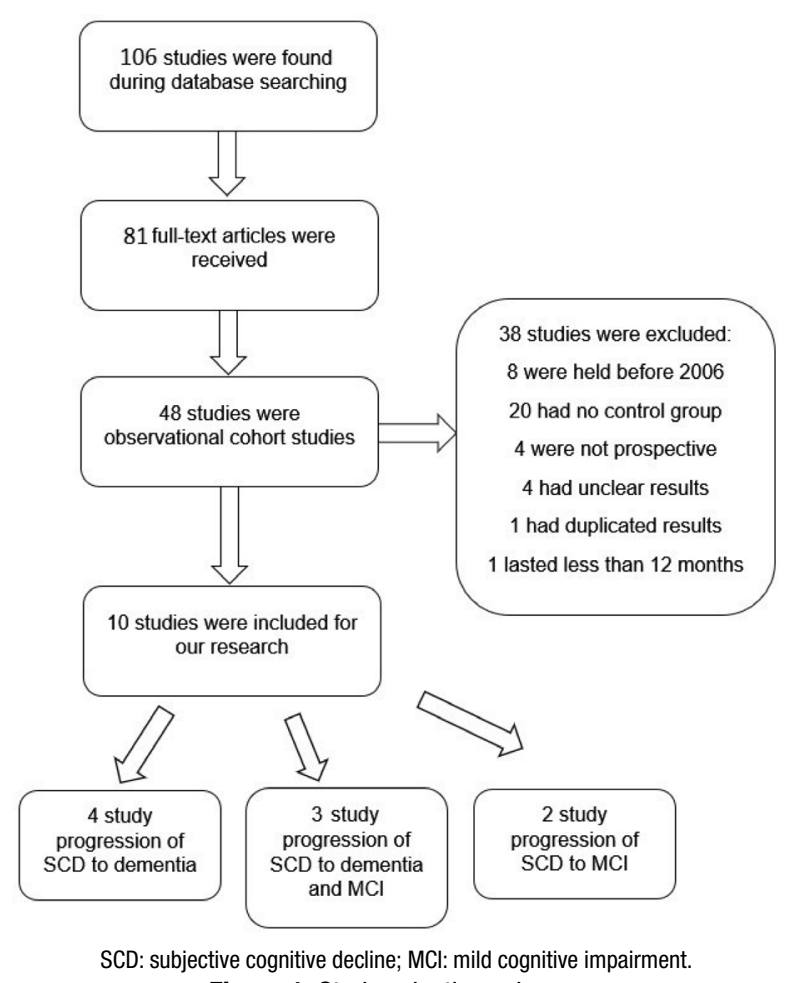

Figure 1. Study selection scheme. 


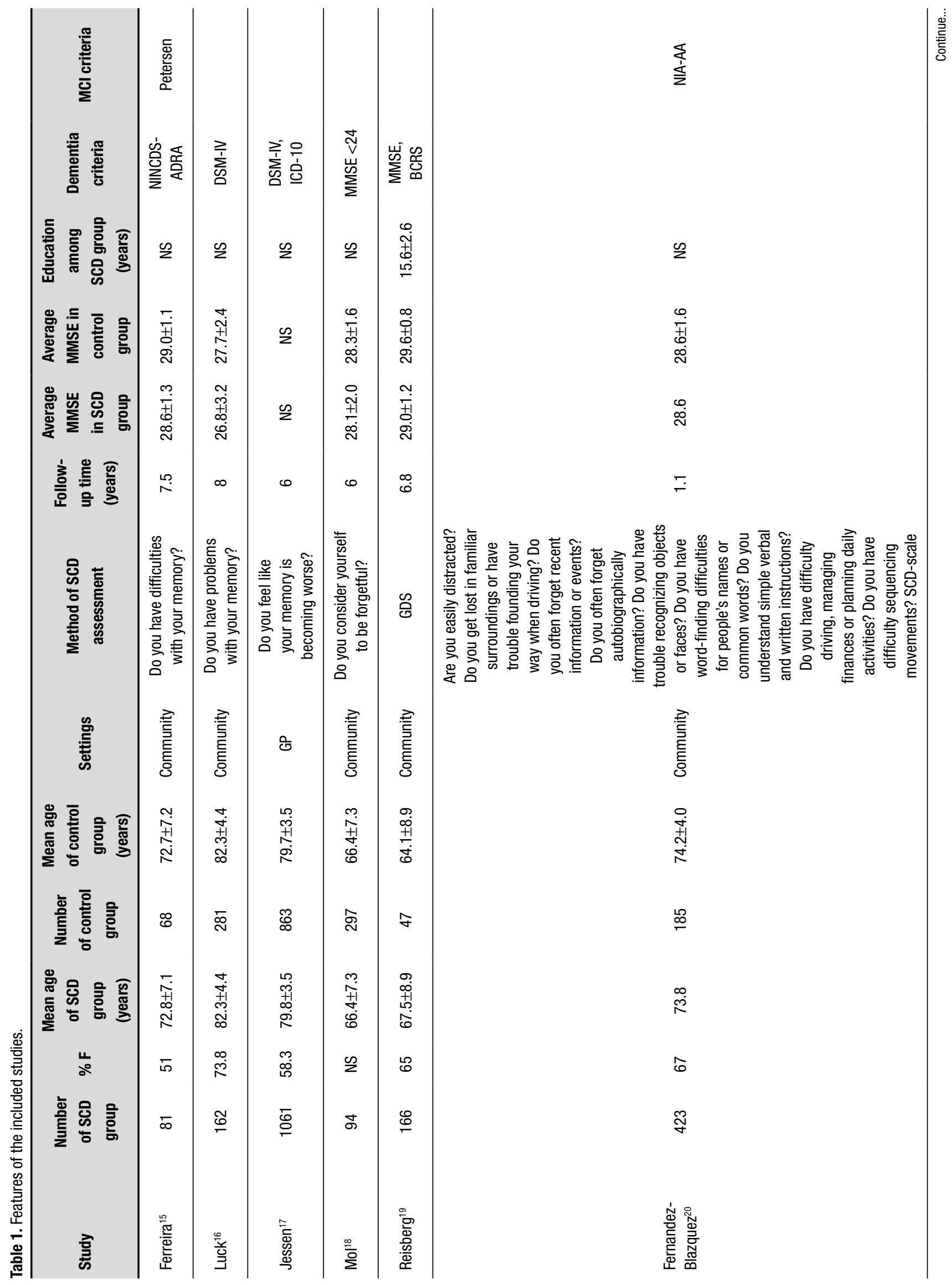




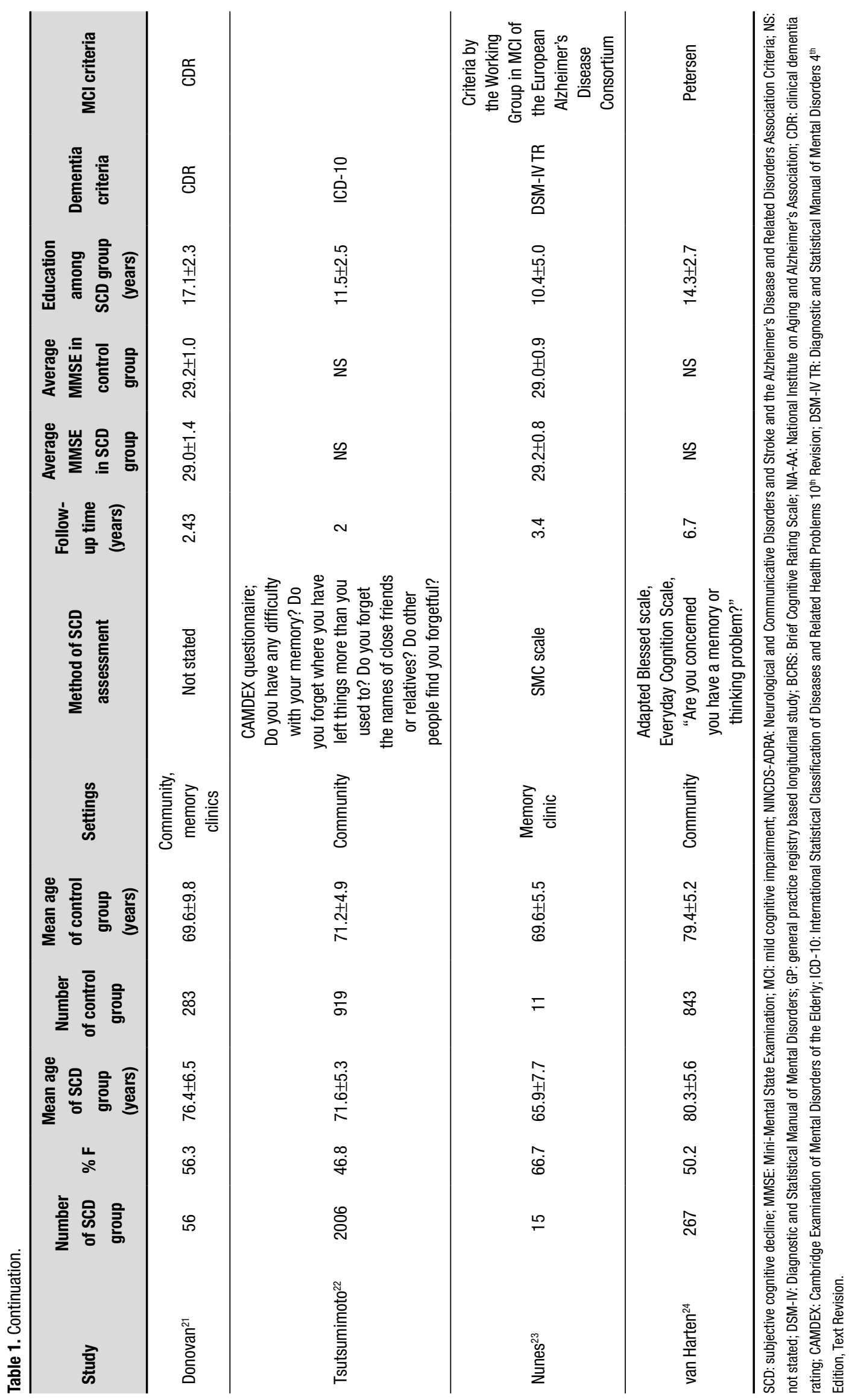


high $\left(I^{2}=92.10 \%\right.$; 95\%CI 87.40-94.50) and there was some evidence of bias (Harbord-Egger bias $=0.60$; $\mathrm{p}=0.87$ ). Annual conversion rate among control group participants was $0.45 \%$ (95\%CI 0.21-0.76).

Relative risk of dementia among patients with SCD compared to those without SCD was 2.17 (95\%CI 1.53-3.07; $\mathrm{p}<0.05$ ) (Figure 3). There was heterogeneity $\left(\mathrm{I}^{2}=11.20 \%\right.$; 95\%CI $\left.0.00-61.00\right)$ and no evidence of bias (Harbord-Egger bias $=1.51 ; \mathrm{p}=0.01$ ). After adjustment for age and gender, relative risk was 2.08 (95\%CI 1.35-2.89).

\section{Analysis of subjective cognitive decline progression to mild cognitive impairment}

The following results were obtained from the analysis of 5 studies.

Cumulative conversion rate of SCD progression to MCI was $20.76 \%$ (95\%CI 9.04-35.73). Heterogeneity was high ( $\mathrm{I}^{2}=96.10 \%$; 95\%CI 93.90-97.20) and there was some evidence of bias (Harbord bias=6.39; $\mathrm{p}=0.44$ ). Annual conversion rate for $\mathrm{MCI}$ in the SCD group was $5.44 \%$ (95\%CI 3.13-8.33). Heterogeneity was high $\left(\mathrm{I}^{2}=64.60 \%\right.$; 95\%CI 0.00-84.40).

Cumulative conversion rate for $\mathrm{MCI}$ in the control group was $8.93 \%$ (95\%CI 6.84-11.28). There was heterogeneity $\left(\mathrm{I}^{2}=36.9 \%, 95 \% \mathrm{CI} 0.00-75.90\right)$ and some evidence of bias (Harbord bias $=-0.83 ; \mathrm{p}=0.55$ ). Annual conversion rate in the control group was $2.75 \%$ (95\%CI 1.51-4.34). Heterogeneity was high $\left(\mathrm{I}^{2}=46.80 \%\right.$; 95\%CI 0.00-78.90).

Relative risk of MCI conversion in SCD compared to control was 2.15 (95\%CI 1.39-3.30; $\mathrm{p}=0.005$ ) (Figure 4). There was considerable heterogeneity $\left(\mathrm{I}^{2}=58.80 \%\right.$; $95 \% \mathrm{CI}$ $0.00-82.60$ ) and some evidence of bias (Harbord-Egger bias $=-0.07 ; \mathrm{p}=0.90)$. After adjustment for age and gender, relative risk was 2.12 (95\%CI 1.10-4.30).

The risk of dementia depended on the dementia criteria used. The highest relative risk of dementia was found in the study that used NINCDS-ADRA criteria and it was $13.88(95 \% \mathrm{CI} 1.59-\infty)$. The lowest relative risk was 1.68 (95\%CI 1.11-2.53) and it was found in the studies that used DSM-IV and ICD-10 criteria (Figure 5).

\section{DISCUSSION}

The main aim of the review was to compare whether people with SCD are more likely to develop cognitive impairment over time than people without SCD. Cumulative risk of conversion to dementia in the SCD group is $7.23 \%$ (95\%CI 3.64-12.04). The relatively low

\section{Proportion meta-analysis plot [random effects]}

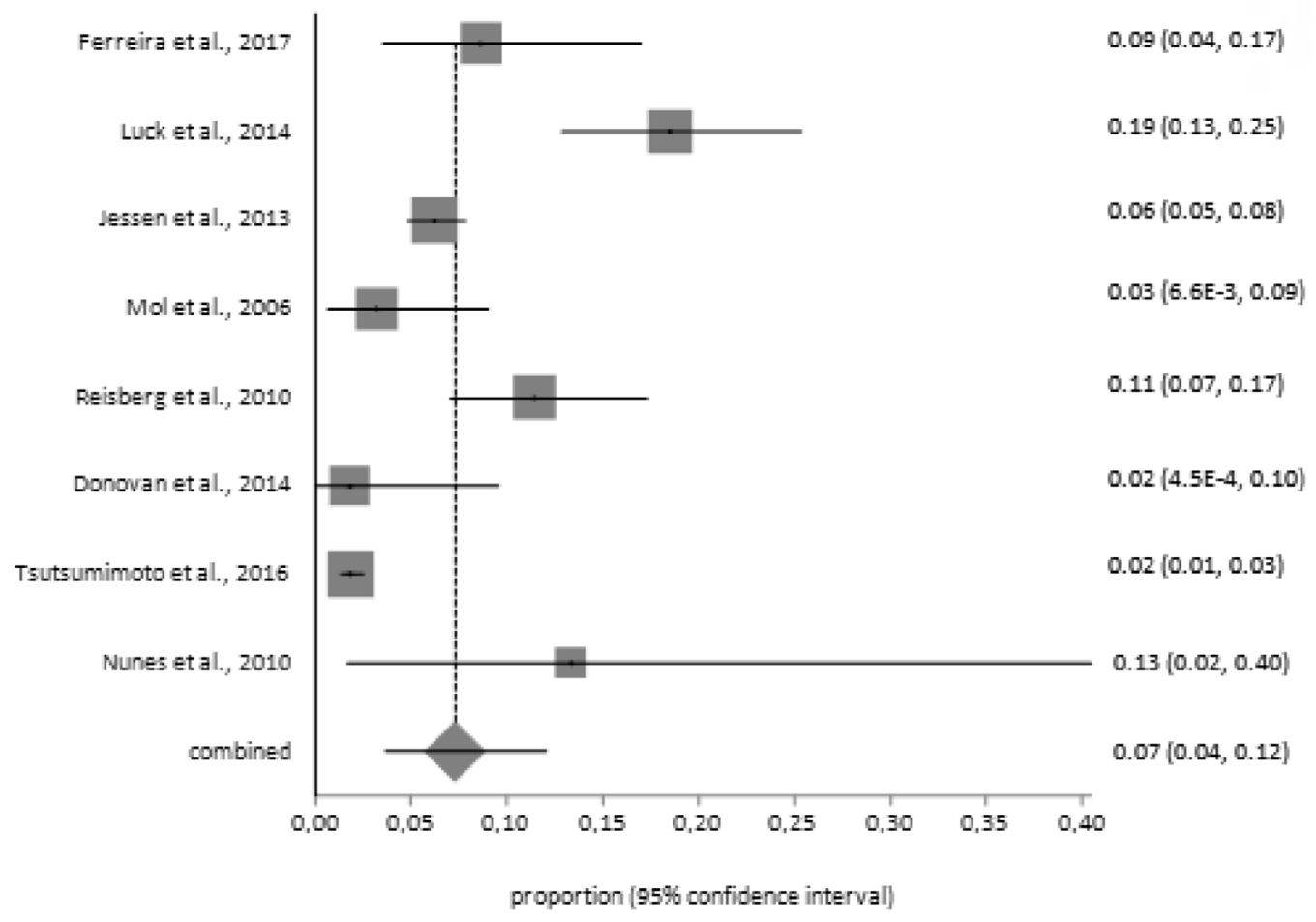

Figure 2. Cumulative conversion rate of subjective cognitive decline to dementia. 


\section{Relative risk meta-analysis plot (random effects)}

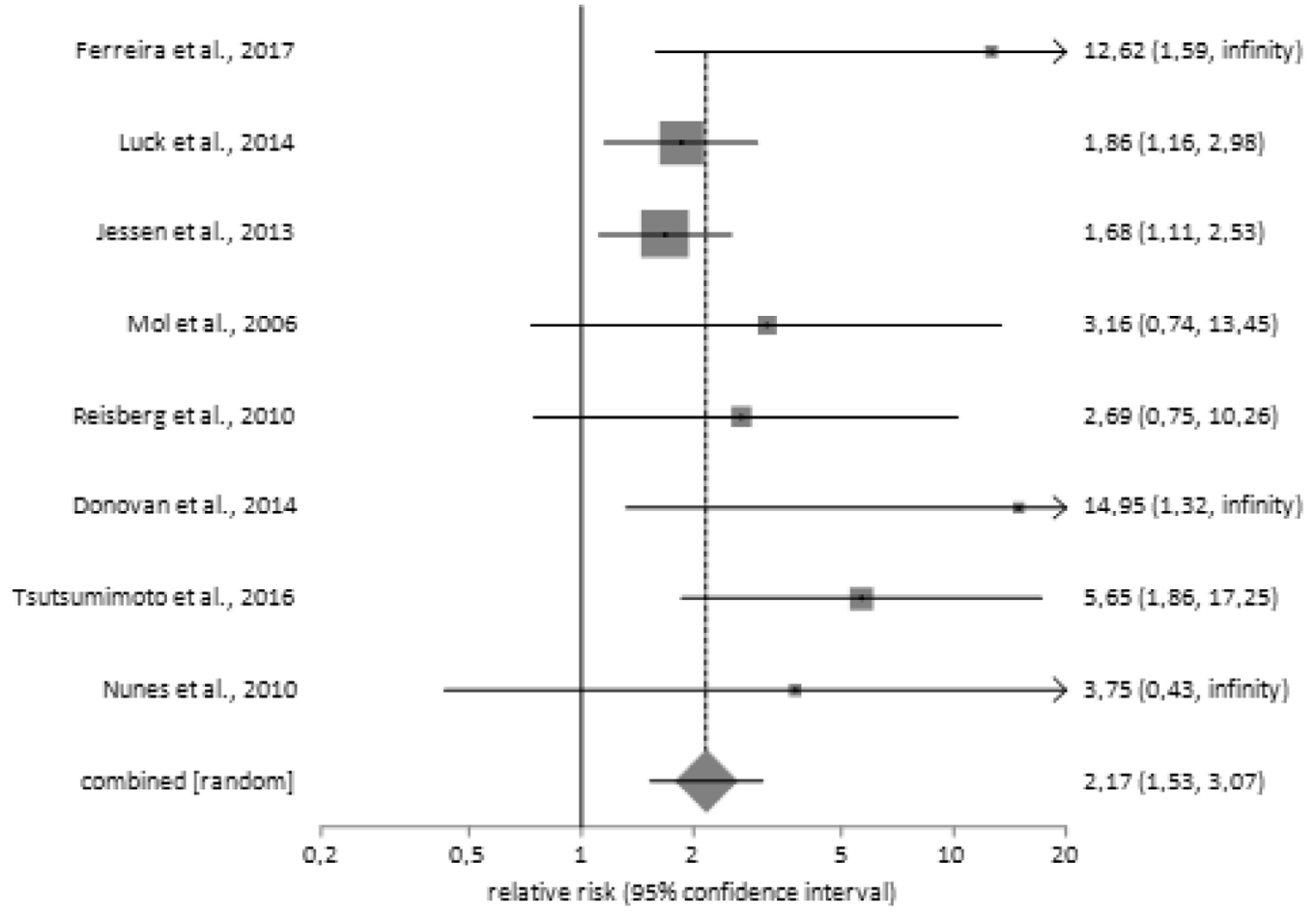

Figure 3. Relative risk of dementia.

\section{Relative risk meta-analysis plot (random effects)}

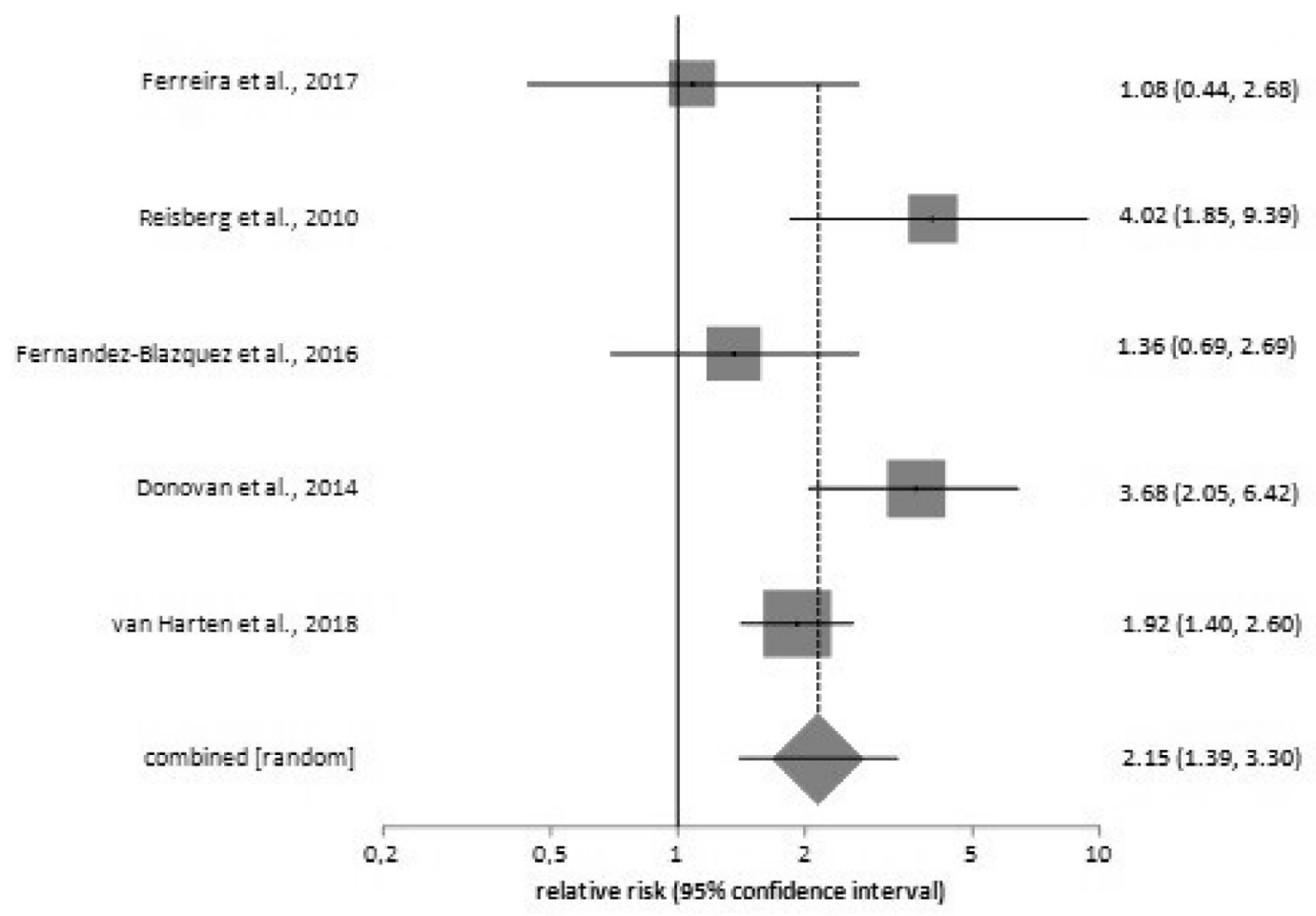

Figure 4. Relative risk of mild cognitive impairment conversion. 
Relative risk plot for different dementia criteria

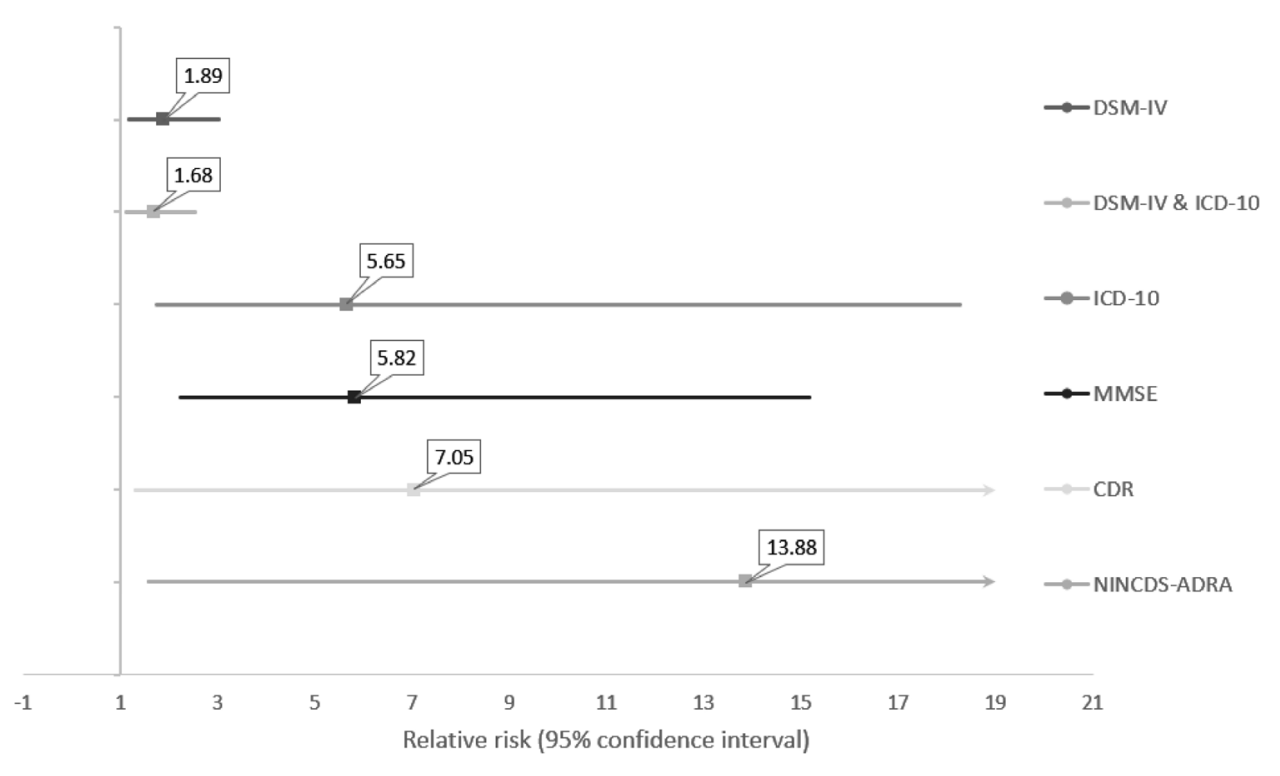

DSM-IV: Diagnostic and Statistical Manual of Mental Disorders; ICD-10: International Statistical Classification of Diseases and Related Health Problems $10^{\text {th }}$ Revision; MMSE: Mini-Mental State Examination; CDR: clinical dementia rating; NINCDS-ADRA: Neurological and Communicative Disorders and Stroke and the Alzheimer's Disease and Related Disorders Association Criteria.

Figure 5. Relative risk plot for different dementia criteria.

risk of dementia conversion might be explained by the short duration of the follow-up period (5.27 years on average). The chance of progression to dementia in the SCD group is $2.17(95 \%$ CI $1.53-3.07 ; \mathrm{p}<0.05)$ compared to normal aging.

The cumulative rate of SCD conversion to $\mathrm{MCI}$ was found to be $20.76 \%$ (95\%CI 9.04-35.73) over 4.91 years. The SCD group was 2.15 times more likely to progress to $\mathrm{MCI}$ than the group without SCD (95\%CI 1.39-3.30; $\mathrm{p}=0.005$ ).

The results of our systematic review demonstrate that people with SCD are characterized by an increased risk of cognitive impairment.

The highest relative risk was found in the study that used NINCDS-ADRA criteria. We cannot offer an exact explanation of this finding. Perhaps, it might be due to the fact that these criteria were used in 1 study with a relatively small number of participants. We suppose that $S C D$ precedes $A D$ in most cases and NINCDS-ADRA criteria are used for $A D$ diagnosis. The $S C D$ and $A D$ connection using NINCDS-ADRA criteria should be considered for further studies.

The assumption that SCD could precede cognitive impairment was confirmed by studies with biomarkers. It was found that individuals with SCD have an increased likelihood of AD-associated biomarker abnormalities. ${ }^{8,25-27}$ A study conducted by Visser et al. showed that SCD patients have AD-predicting CSF profile (low $\mathrm{A} \beta-42$ and high tau levels) more often than control ones. ${ }^{28}$ These biomarkers are associated with a greater risk of $\mathrm{MCI}$ and dementia and, thus, SCD may expand indications for $\mathrm{AD}$ biochemical and bioimaging diagnostic screening.

Some SCD neuroimaging studies have been reported. Van der Flier et al. showed that individuals with SCD have a lesser left hippocampal volume than individuals without complaints. ${ }^{29}$ Another study found that SCD and amnestic MCI patients have similar MRI changes, including atrophy of the medial temporal and frontotemporal regions, correlating these findings with the severity of $\mathrm{SCD} .{ }^{30}$ Several fluorodeoxyglucose positron emission tomography (FDG-PET) studies identified hypometabolism in the parahippocampal gyrus, middle temporal gyrus, left inferior parietal lobe, inferior frontal gyrus, fusiform gyrus, thalamus, and in the right putamen $^{31,32}$ in people with SCD.

SCD could be the earliest preclinical phase of dementing disorders in some patients. In particular, the beginning of dementia should be suspected in individuals who have memory complaints along with other dementia risk factors. However, the results of our study demonstrated that about $7 \%$ of people with 
SCD will have objective cognitive impairment in 5 years. This conversion rate is relatively low and there is no strong evidence that these patients should be treated as patients with cognitive impairment.

We did not investigate the relationship between SCD and depression, but we should note that several studies showed that individuals with higher depressive symptoms showed significant SCD-cognition association. ${ }^{33,34}$

Our study discovered that $2.75 \%$ of healthy subjects without SCD annually convert to MCI. These results should be considered along with the fact that MCI does not inevitably turn into dementia, but the reversion rate of $\mathrm{MCI}$ is high and ranges from 30 to $50 \%$ within two to five years of follow-up. ${ }^{35}$

One relevant issue is the lack of a standard definition of SCD and SCD criteria. Included studies used distinct SCD scales and assessment methods with different questions. Different cognitive complaints may affect the results of the study.

This study was not the first systematic review of SCD clinical data. A review performed by Mitchell et al. evaluated whether people with SCD are at increased risk of MCI and dementia. ${ }^{36}$ The authors included 32 studies, but there were some old studies that could impact the meta-analysis results due to misdiagnosis. In addition, not all the included studies had control groups, so the results of SCD groups were not compared to healthy controls. The annual conversion rate for $\mathrm{MCI}$ and dementia was slightly higher in comparison to our results. However, the relative risk of dementia conversion was 2.07. These results are close to our findings. Another meta-analysis performed by Burmester et al. was a large quantitative and qualitative synthesis of researches. ${ }^{37}$ However, the authors did not evaluate the annual conversion rate or relative risks of objective cognitive decline.

Our systematic review has some limitations. First, we had a relatively limited data set due to our strict inclusion criteria for the studies. Secondly, our review had heterogeneous data and some evidence of bias in the obtained results. High heterogeneity might be caused by different study settings and criteria used for the diagnosis. Evidence of bias can be explained by a relatively small number of included studies. Furthermore, some studies included a small number of participants.

Despite the limitations mentioned, the results of our systematic review demonstrate that patients with SCD have an increased risk of MCI or dementia. SCD is a risk group for $\mathrm{MCI}$ and dementia, and therefore worthy of further investigation and consideration for trials of new treatments.

Author's contributions. VAP: conceptualization, supervision; VVZ: conceptualization, methodology; ARK: conceptualization, investigation; NVV: conceptualization, project administration.

\section{REFERENCES}

1. Prince M, Bryce R, Albanese E, Wimo A, Ribeiro W, Ferri CP. The global prevalence of dementia: a systematic review and meta-analysis. Alzheimers Dement. 2013;9(1):63-75.e2. https://doi.org/10.1016/j. jalz.2012.11.007

2. Abdulrab K, Heun $R$. Subjective memory impairment a review of its definitions indicates the need for a comprehensive set of standardised and validated criteria. Eur Psychiatry. 2008;23(5):321-30. https://doi. org/10.1016/j.eurpsy.2008.02.004

3. Mitchell AJ. Is it time to separate subjective cognitive complaints from the diagnosis of mild cognitive impairment? Age Ageing. 2008;37(5):497-99. https://doi.org/10.1093/ageing/afn147

4. Mitchell AJ. The clinical significance of subjective memory complaints in the diagnosis of mild cognitive impairment and dementia: a meta-analysis. Int $J$ Geriatr Psychiatry. 2008;23(11):1191-202. https://doi.org/10.1002/gps.2053

5. Mitchell AJ. A meta-analysis of the accuracy of the minimental state examination in the detection of dementia and mild cognitive impairment. J Psychiatr Res. 2009;43(4):411-43. https://doi.org/10.1016/j.jpsychires.2008.04.014

6. Reisberg B, Ferris SH, de Leon MJ, Crook T. The Global Deterioration Scale for assessment of primary degenerative dementia. Am J Psychiatry. 1982;139(9):1136-9. https://doi.org/10.1176/ajp.139.9.1136

7. Reisberg B. Dementia: a systematic approach to identifying reversible causes. Geriatrics 1986;41(4):30-46

8. Jessen F, Amariglio RE, van Boxtel M, Breteler M, Ceccaldi M, Chételat G, et al. A conceptual framework for research on subjective cognitive decline in preclinical Alzheimer's disease. Alzheimers Dement. 2014;10(6):844-52. https://doi.org/10.1016/j.jalz.2014.01.001

9. Cooper C, Bebbington P, Lindesay J, Meltzer H, McManus S, Jenkins R, et al. The meaning of reporting forgetfulness: a cross-sectional study of adults in the English 2007 Adult Psychiatric Morbidity Survey. Age Ageing 2011;40(6):711-17. https://doi.org/10.1093/ageing/afr121

10. Jonker C, Geerlings MI, Schmand B. Are memory complaints predictive for dementia? A review of clinical and population-based studies. Int J Geriatr Psychiatry. 2000;15(11):983-91. https://doi.org/10.1002/ 1099-1166(200011)15:11\%3C983::aid-gps238\%3E3.0.co;2-5

11. Slavin MJ, Brodaty H, Kochan NA, Crawford JD, Trollor JN, Darper B, et al. Prevalence and predictors of "subjective cognitive complaints" in the Sydney Memory and Ageing Study. Am J Geriatr Psychiatry. 2010;18(8):701-10. https://doi.org/10.1097/jgp.0b013e3181df49fb

12. Mewton L, Sachdev P, Anderson T, Sunderland M, Andrews G. Demographic, Clinical, and Lifestyle Correlates of Subjective Memory Complaints in the Australian Population. Am J Geriatr Psychiatry. 2014;22(11):1222-32. https://doi.org/10.1016/j.jagp.2013.04.004 .

13. Merema MR, Speelman CP, Foster JK, Kaczmarek EA. Neuroticism (not depressive symptoms) predicts memory complaints in some community-dwelling older adults. Am J Geriatr Psychiatry. 2013;21(8):729-36. https://doi.org/10.1016/j.jagp.2013.01.059

14. Petersen RC, Smith GE, Waring SC, Ivnik RJ, Tangalos EG, Kokmen E. Mild cognitive impairment: clinical characterization and outcome. Arch Neurol. 1999; 56:303-8. https://doi.org/10.1001/archneur.56.3.303

15. Ferreira D, Falahati F, Linden C, Buckley RF, Ellis KA, Savage G, et al. A 'Disease Severity Index' to identify individuals with Subjective Memory Decline who will progress to mild cognitive impairment or dementia. Sci Rep. 2017;13:7:44368. https://doi.org/10.1038/srep44368

16. Luck T, Luppa M, Matschinger H, Jessen F, Angermeyer MC, Riedel-Heller SG. Incident subjective memory complaints and the risk of subsequent dementia. Acta Psychiatr Scand. 2015;131(4):290-6. https://doi. org/10.1111/acps. 12328 
17. Jessen F, Wolfsgruber S, Wiese B, Bickel H, Mösch E, Kaduszkiewicz $\mathrm{H}$, et al. $A D$ dementia risk in late $\mathrm{MCl}$, in early $\mathrm{MCl}$, and in subjective memory impairment. Alzheimers Dement. 2014;10(1):76-83. https://doi. org/10.1016/j.jalz.2012.09.017

18. Mol ME, van Boxtel MP, Willems D, Jolles J. Do subjective memory complaints predict cognitive dysfunction over time? A six-year follow-up of the Maastricht Aging Study. Int J Geriatr Psychiatry. 2006;21(5):432-41. https://doi.org/10.1002/gps.1487

19. Reisberg B, Shulman MB, Torossian C, Leng L, Zhu W. Outcome over seven years of healthy adults with and without subjective cognitive impairment. Alzheimers Dement. 2010;6(1):11-24. https://doi.org/10.1016/j. jalz.2009.10.002

20. Fernandez-Blazquez MA, Avila-Villanueva M, Maestu F, Medina M. Specific features of subjective cognitive decline predict faster conversion to mild cognitive impairment. J Alzheimers Dis. 2016;52(1):271-81. https://doi. org/10.3233/jad-150956

21. Donovan NJ, Amariglio RE, Zoller AS, Rudel RK, Gomez-Isla T, Blacker D, et al. Subjective cognitive concerns and neuropsychiatric predictors of progression to the early clinical stages of Alzheimer disease. Am J Geriatr Psychiatry. 2014.22(12):1642-51. https://doi.org/10.1016/j.jagp.2014.02.007

22. Tsutsumimoto K, Makizako H, Doi T, Hotta R, Nakakubo S, Makino K, et al. Subjective memory complaints are associated with incident dementia in cognitively intact older people, but not in those with cognitive impairment: a 24-month prospective cohort study. Am J Geriatr Psychiatry. 2017;25(6):607-16. https://doi.org/10.1016/j.jagp.2016.12.008

23. Nunes T, Fragata I, Ribeiro F, Palma T, Maroco J, Cannas J, et al. The outcome of elderly patients with cognitive complaints but normal neuropsychological tests. J Alzheimers Dis 2010;19(1):137-45. https://doi. org/10.3233/jad-2010-1210

24. van Harten AC, Mielke MM, Swenson-Dravis DM, Hagen CE, Edwards $\mathrm{KK}$, Roberts $\mathrm{RO}$, et al. Subjective cognitive decline and risk of $\mathrm{MCl}$ : The Mayo Clinic Study of Aging. Neurology. 2018;91(4):e300-e312. https:// doi.org/10.1212/WNL.0000000000005863

25. Mielke MM, Wiste HJ, Weigand SD, Knopman DS, Lowe VJ, Roberts $\mathrm{RO}$, et al. Indicators of amyloid burden in a population-based study of cognitively normal elderly. Neurology. 2012;79(15):1570-7. https://doi. org/10.1212/WNL.0b013e31826e2696

26. Stewart R, Godin O, Crivello F, Maillard P, Mazoyer B, Tzourio C, et al. Longitudinal neuroimaging correlates of subjective memory impairment: 4-year prospective community study. Br J Psychiatry. 2011;198(3):199-205. https://doi.org/10.1192/bjp.bp.110.078683

27. Sun Y, Yang FC, Lin CP, Han Y. Biochemical and neuroimaging studies in subjective cognitive decline: progress and perspectives. CNS Neurosci Ther. 2015;21(10):768-75. https://doi.org/10.1111/cns.12395
28. Visser $P J$, Verhey $F$ Knol DL, Scheltens $P$, Wahlund LO, Freund-Levi $Y$, et al. Prevalence and prognostic value of CSF markers of Alzheimer's disease pathology in patients with subjective cognitive impairment or mild cognitive impairment in the DESCRIPA study: A prospective cohort study. Lancet Neurol. 2009;8(7):619-27. https://doi.org/10.1016/s14744422(09)70139-5

29. van der Flier WM, van Buchem MA, Weverling-Rijnsburger AW, Mutsaers ER, Bollen EL, Admiraal-Behloul F, et al. Memory complaints in patients with normal cognition are associated with smaller hippocampal volumes. J Neurol. 2004;251(6):671-5. https://doi.org/10.1007/ s00415-004-0390-7

30. Saykin AJ, Wishart HA, Rabin LA, Santulli RB, Flashman LA, West JD, et al. Older adults with cognitive complaints show brain atrophy similar to that of amnestic MCl. Neurology. 2006;67(5):834-42. https://doi.org/10.1212/01. wnl.0000234032.77541.a2

31. Mosconi L, De Santi S, Brys M, Tsui WH, Pirraglia E, Glodzik-Sobanska $L$, et al. Hypometabolism and altered cerebrospinal fluid markers in normal apolipoprotein E E4 carriers with subjective memory complaints. Biol Psychiatry. 2008;63(6):609-18. https://doi.org/10.1016/j.biopsych.2007.05.030

32. Mistur R, Mosconi L, Santi SD, Guzman M, Li Y, Tsui W, et al. Current challenges for the early detection of Alzheimer's disease: Brain imaging and CSF studies. J Clin Neurol. 2009;5(4):153-66. https://doi.org/10.3988/ jcn.2009.5.4.153

33. Alegret M, Rodríguez O, Espinosa A, Ortega G, Sanabria A, Valero S, et al. Concordance between subjective and objective memory impairment in volunteer subjects. J Alzheimers Dis. 2015;48(4):1109-17. https://doi. org/10.3233/jad-150594

34. Seo EH, Kim H, Choi KY, Lee KH, Choo IH. Association of subjective memory complaint and depressive symptoms with objective cognitive functions in prodromal Alzheimer's disease including pre-mild cognitive impairment. J Affect Disord. 2017;217:24-8. https://doi.org/10.1016/j. jad.2017.03.062

35. Pandya SY, Clem MA, Silva LM, Woon Fl. Does mild cognitive impairment always lead to dementia? A review. J Neurol Sci. 2016;369:57-62. https:// doi.org/10.1016/j.jns.2016.07.055

36. Mitchell AJ, Beaumont $H$, Ferguson D, Yadegarfar M, Stubbs B. Risk of dementia and mild cognitive impairment in older people with subjective memory complaints: meta-analysis. Acta Psychiatr Scand. 2014;130(6):439-51. https://doi.org/10.1111/acps.12336

37. Burmester B, Leathem J, Merrick P. Subjective cognitive complaints and objective cognitive function in aging: a systematic review and meta-analysis of recent cross-sectional finding. Neuropsychol Rev. 2016;26(4):376-93. https://doi.org/10.1007/s11065-016-9332-2 